\title{
TUNING AND MATCHING OF THE BPX ICH SYSTEM*
}

\author{
D. W. Swain \\ Oak Ridge National Laboratory, Oak Ridge TN 37831-8071, USA
}

\section{ABSTRACT}

Two methods of tuning and matching the ion cyclotron heating (ICH) antennas for the Burning Plasma Experiment (BPX) to the BPX plasma have been analyzed. Both appear to provide adequate tuning and matching capabilities. However, there are tradeoffs between the frequency range that can be covered and the compactness of the highvoltage region of the transmission lines that makes up part of the matching network.

\section{INTRODUCTION AND BASELINE DESIGN}

The BPX ICH system must transmit at least $20 \mathrm{MW}$ to the plasma under a wide variety of densities and density profiles (both $\mathrm{L}$ - and $\mathrm{H}$ - mode) and must be able to respond dynamically to changes in the antenna loading caused by changes in plasma parameters. The ICH system must also operate over a range of frequencies in the 50 - to $90-\mathrm{MHz}$ range, corresponding to the different magnetic fields and heating modes that will be employed. In addition, it must operate in the neutron and gamma radiation environment that will be present around BPX.

The BPX ICH system uses four horizontal midplane ports for access to the plasma. Each port contains four independently driven current straps, each of which is connected to a tuning and matching circuit and, through a transmission line, to an if power unit. A schematic diagram of the circuit for one strap is shown in Fig. 1.

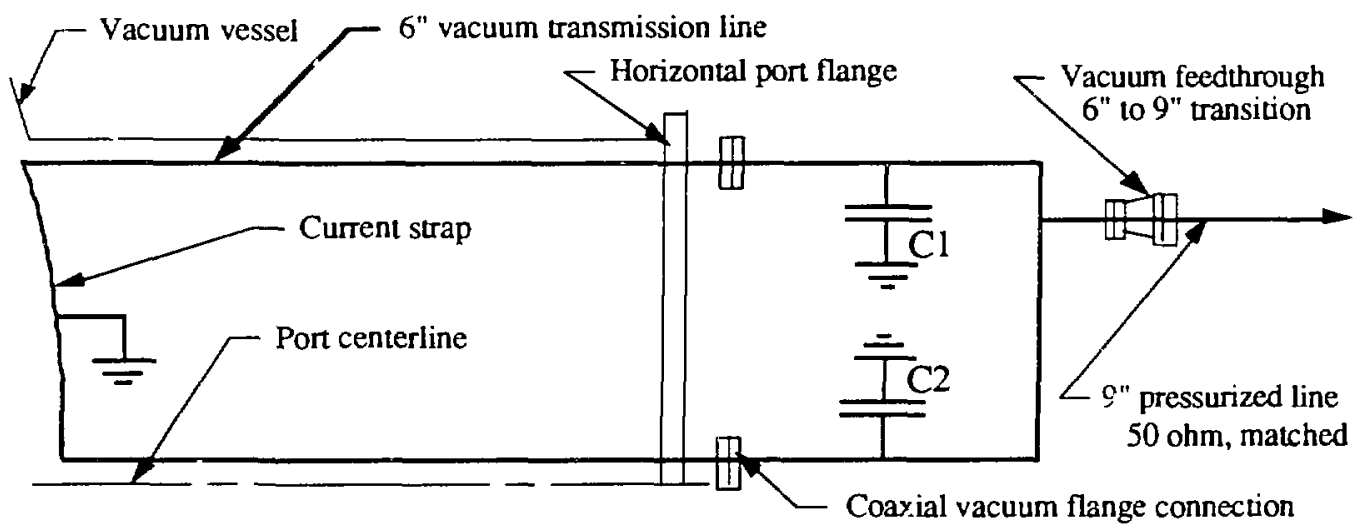

Fig. 1. Schematic layout of the BPX ICH antenna system.

Each strap is grounded at the center and fed at both ends. Vacuum coax $(6$ in. in diameter) goes tisrough the horizontal port flange, where the lengths of coax driving the two ends are connected into a capacitively tuned resonant loop (RL) circuit. By changing the values of the two capacitors $\mathrm{C} 1$ and $\mathrm{C} 2$, the circuit can be tuned over

\footnotetext{
* Research sponsored by the Office of Fusion Energy, U.S. Department of Energy, under contract DE-AC05-84OR21400 with Martin Marietta Energy Systems, Inc.
} 
limited frequency bands and matched for a range of plasma loading values, so that the load at the 6-in. to 9-in. transition appears to be $50 \mathrm{ohms}$.

Figure 2 indicates resonant frequencies of possible minority species vs magnetic field. The tuning ranges of the RL are indicated by shaded bands, showing that nominal

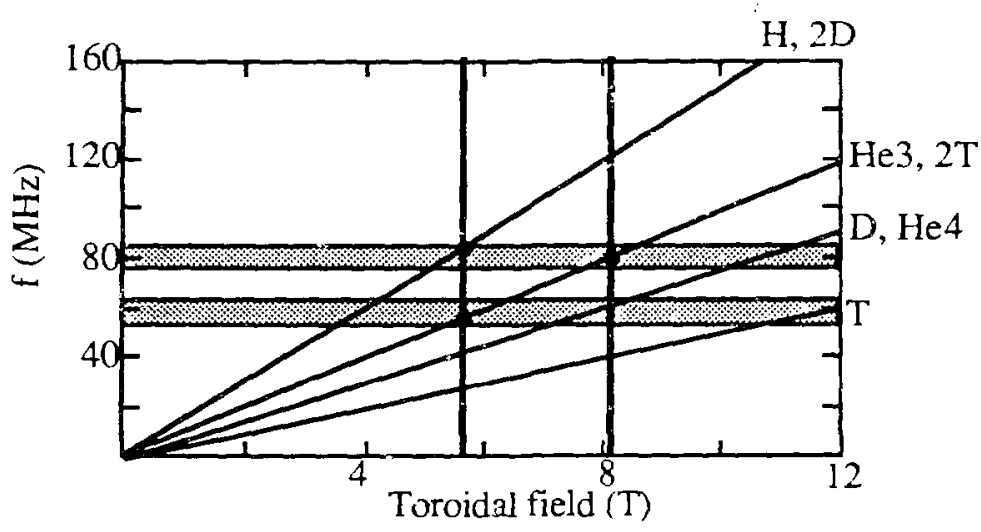

Fig. 2. BPX operating regimes. operation at the design field of $8.1 \mathrm{~T}$ can be attained using $\mathrm{He}^{3}$ minority heating and that, at $\sim 2 / 3$ design field, operation can be attained using both $\mathrm{He}^{3}$ and $\mathrm{H}$ minority heating. The if power units will be designed to tune continuously over the 50- to 100 $\mathrm{MHz}$ range.

The plasma loading has been calculated by Batchelor et al. ${ }^{1}$ for a wide variety of plasma conditions. Figure 3 shows the theoretical loading resistance (ohms per meter of antenna length) calculated vs the distance from the plasma

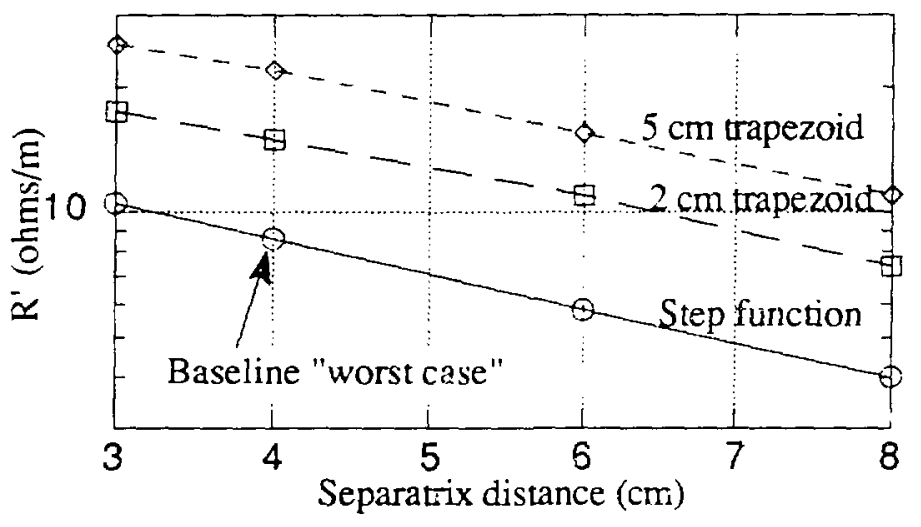

Fig. 3. Loading resistance vs separatrix position for different plasma profiles, $\mathrm{n}=4.4 \times 10^{20} \mathrm{~m}^{-3}$. separatrix for several different plasma profiles. The taseline "worst case" loading of $8.3 \mathrm{ohms} / \mathrm{m}$ corresponds to a step function, highdensity $\left(4.4 \times 10^{20} \mathrm{~m}^{-3}\right)$ case corresponding to an $H$-mode plasma near the density limis at the nominal separatrix position. For other profiles, shown by the dashed lines, loading values up to $24 \mathrm{ohms} / \mathrm{m}$ can be attained. Thus, the tuning and matching network must be able to

accommodate changes in loading of up to a factor of three during a shot.

For the circuit parameters chosen for the design, the current and voltage in the 6-in.vacuum transmission line are within the present state of the art. For a loading resistance of $8.3 \mathrm{ohms} / \mathrm{m}$ and a power of $1.25 \mathrm{MW}$ from one strap (resulting in $20 \mathrm{MW}$ to the plasma through four ports), the calculated peak voltage in the transmission line is $\approx 33 \mathrm{kV}$ and occurs $\approx 0.5 \mathrm{~m}$ down the transmission line from the current strap. For these calculations, the current strap is assumed to have a characteristic impedance of 46 ohms and a phase velocity along the strap of $0.67 \mathrm{c}$ (the decrease in the phase velocity 
being caused by the capacitive loading of the current strap by the Faraday shield); these values correspond to experimentaily measured values on the TFTR Bay L antenna. The vacuum transmission line, has a 30-ohm characteristic impedance.

\section{DYNAMIC MATCHING}

From calculations and measurements on existing $\mathrm{H}$-mode tokamaks with $\mathrm{ICH}, 2,3$ the load resistance can change by a factor of three during a shot. The present plans for the BPX system to accommodate these changes are:

1. Design the power units with automatic power control, so that if enough power is reflected back to the power unit to cause damage to the output tube, the power will be reduced in a short time. This is now standard practice in plasma if heating experiments and will be continued for BPX.

2. Design a robust system that will operate at all times with the capability to withstand a VSWR of 1.5. This will limit the maximum power available to approximately $2 / 3$ of the installed transmitter power, but the resulting VSWR and reserve power capability should result in a much more reliable system.

3. Utilize plasma position control for fast compensation for changes in $\mathrm{R}^{\prime}$. This has worked very well on JET, ${ }^{4}$ and initial calculations indicate that a fast time response ( $\leq 200 \mathrm{~ms}$ ) should be possible on BPX.

4. Implement automated mechanical tuning of the matching circuit to adjust the match in $\leq 1 \mathrm{~s}$. If possible, decrease the response time to $\sim 0.1 \mathrm{~s}$.

5. Shift the if frequency by as much as $\pm 100 \mathrm{kHz}$ to compensate for changes in the current strap inductance.

Figure 4 shows the changes in $\mathrm{C} 1$ and $\mathrm{C} 2$ required to match the RL circuit back to

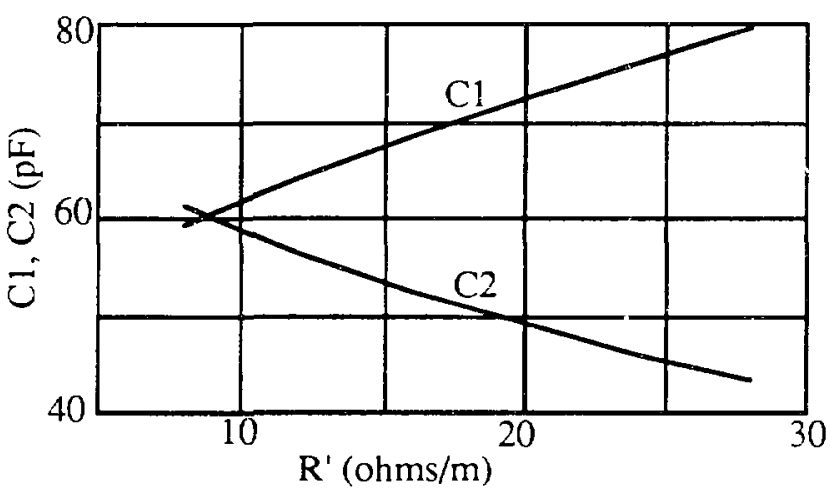

Fig. 4. Capacitance values vs plasma load required to match the $R L$ circuit at $f=80 \mathrm{MHz}$.
50 ohms as the plasma loading changes. As can be seen, the changes are relatively modest, and servo-driven vacuum capacitors should be able to change the values in $<1 \mathrm{~s}$ and possibly in $\sim 0.1$ s.

\section{CONTINUOUSLY TUNED DESIGN}

An alternative to the

$R L$ matching system is the design shown in Fig. 5. It is a straightforward design that uses more components but provides the capability to tune and match the antenna system over the entire 50 - to 100 $\mathrm{MHz}$ band. It can also be used to dynamically match by changing the capacitors and frequency, although the change in the capacitors needed is generally higher than for the RL circuit. Voltage and current in this system are the same as for the RL design.

The primary disadvantage of this circuit is due to the radiation environment anticipated around BPX. To allow hands-on access for maintenance, the line stretchers and tuning capacitors are located in the BPX basement, which means that the distance from the antenna to the line stretcher will be $\sim 12 \mathrm{~m}$, thus more than doubling the length 
of the transmissic s, ine with high VSWR. In addition, the location of these components in the basement results in the use of significant space in an already crowded area.

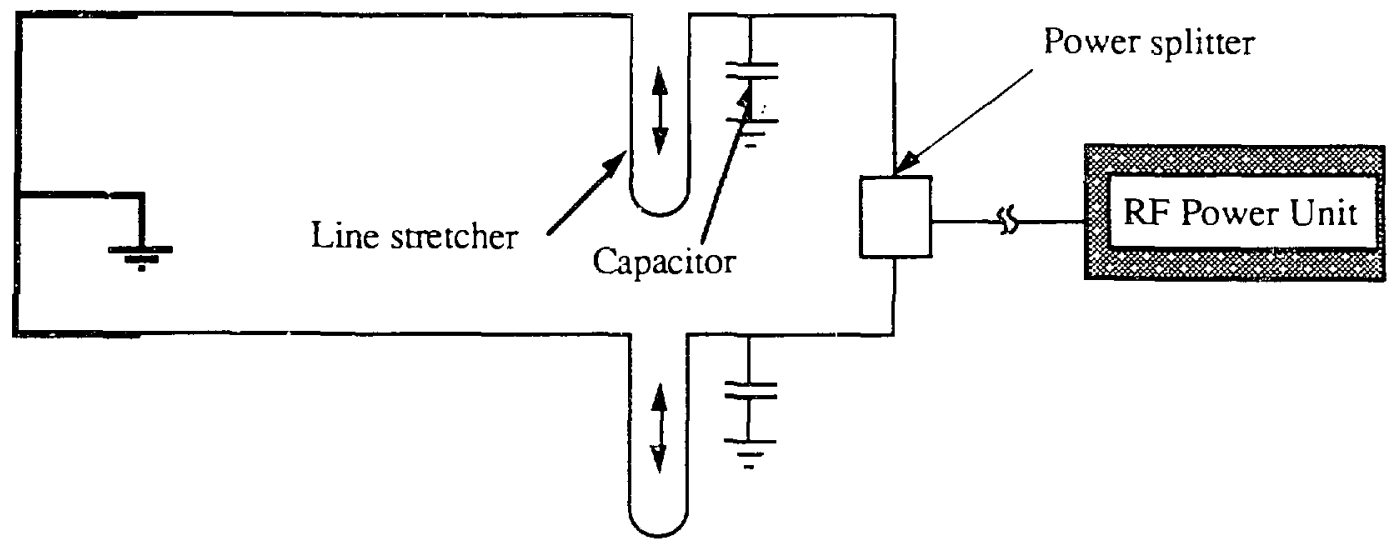

Fig. 5. Schematic diagram of a continuously tuned tuning and matching system.

\section{CONCLUSIONS}

Two antenna tuning and matching rnechanisms, both of which meet the rinimum needs of the BPX system, have been described. The advantages of the baseline RL system are that it is (relatively) compact and the high-VSWR, high-voltage region is contained entirely within the vacuum coax portion of the system. Its primary disadvantage is its inability to tune continuously over the 50 - to $100-\mathrm{MHz}$ range without changing mechanical components (e.g., changing the length of the line inside the resonant loop).

The primary advantage of the continuously tuned system is that it can cover the entire 50- to $100-\mathrm{MHz}$ band, at the expense of increased requirements for space and high-voltage, high-VSWR regions in pressurized 'ransmission lines. Both can dynamically match the changing BPX plasma loading. Further study of the operationaI requirements is required to choose the best design for $\mathrm{B}$ ?X.

\section{REFERENCES}

1 D. B. Batchelor et al., in Proc. 18th European Conf. on Controlled Fusion and Plasma Physics, Berlin, 3-7 June 1991 (European Physical Society, Petit-Laney, Switzerland, 1991), Vol. 15C, Part I; p. 113.

2 T. J. Wade et al., in Proc. 12th Symposium on Fusion Engineering, Monterey CA, 12-16 October 1987 (IEEE, New York, 1987), p. 1200.

3 M. J. Mayberry et al., Nucl. Fusion 30, 579 (1990).

4 V. P. Bhatnagar et al., in Proc. 18th European Conf. on Controlled Fusion and Plasma Physics, Berlin, 3-7 June 1991 (European Physical Society, Petit-Laney, Switzerland, 1991), Vol. 15C, Part I, p. 369.

\section{DISCLAIMER}

This repont was prepared as an account of work sponsored by an agency of the United States Government. Neither the United States Government nor any agency thereof, nor any of their employees, makes any warranty, express or implied, or assumes any legal liability or responsibility for the accuracy, completeness, or usefulness of any information, apparatus, product, or process disclosed, or represents that its use would not infringe privately owned rights. Reference herein to any specific commercial product, process, or service by trade name, trademark, manufacturer, or otherwise does not necessarily constitute or imply its endorsement, recommendation, or favoring by the United States Government or any agency thereof. The views and opinions of authors expressed herein do not necessarily state or reflect those of the United States Government or any agency thereof. 